\title{
Carbon-negative emissions: Systemic impacts of biomass conversion
}

\author{
A case study of $\mathrm{CO}_{2}$ capture and storage options
}

\author{
Jens Hetland ${ }^{a}$, Ping Yowargana ${ }^{b}$, Sylvain Leduc ${ }^{b}$, Florian Kraxner ${ }^{b}$ \\ a) SINTEF Energy Research, Trondheim, Norway \\ b) Ecosystems Services and Management (ESM), International Institute for Applied Systems Analysis \\ (IIASA), Laxenburg, Austria
}

\begin{abstract}
This paper is a contribution to the ongoing debate on carbon-negative energy solutions. It deals with biomass conversion in dedicated biopower plants equipped with CCS (BECCS), or co-fired plants retrofitted with $\mathrm{CCS}$ in order to generate negative $\mathrm{CO}_{2}$-emissions. In this context, bioenergy refers to the use of biomass to generate electricity (i.e. biopower) in compliance with the needs of nations and regions without seasonal space heating demand. In this paper, direct-fired and co-fired systems will be addressed, combined mainly with post-combustion flue gas cleaning. The question is which CCS alternative should be preferred in order to obtain negative emissions: either building multiple smaller biopower units, or employing co-firing of biomass and coal in existing large coal power plants. Based on efficacy and the potential for mitigating greenhouse gas emissions as key indicators, some major differences between the alternatives are shown. In the event that a coal power plant equipped with CCS is readily available, more net electric energy (in MWh) can be provided from the feedstock of biomass than would be obtainable from a dedicated BECCS plant, although the amount of $\mathrm{CO}_{2}$ captured and stored from the biomass (per tonne) will be essentially the same. Further casespecific cost-benefit analyses will be required to determine the feasibility of carbon-negative energy solutions. Although the study is carried out from the perspective of actual biomass sources as regards biomass composition and available technology (i.e. expected efficiency levels) using Indonesian agricultural residues, its main conclusion is fairly general.
\end{abstract}

Keywords: Biopower; bioenergy; $B E C C S ; \mathrm{CO}_{2}$ capture; CCS; co-firing; efficiency; $\mathrm{CO}_{2}$ mitigation; negative emissions.

\section{Introduction}

The paper summarises a case-based study aimed at estimating the efficacy of biomass conversion into electric power given the chemical composition of candidate feedstocks. Emphasis is placed on a) net electricity, i.e. electric power and electric energy supplied to the grid (in $\mathrm{MW}_{\mathrm{e}}$ and $\mathrm{MWh}$ ), and b) the resulting greenhouse gas emissions, as to how the atmosphere is eventually affected. In this endeavour, two principles apply: one co-firing biomass and coal in large coal power plants, the other 
firing biomass in dedicated biopower plants (BECCS). Both principles employ absorption techniques cleaning the flue gas (CCS). This includes compression to supercritical pressure of the $\mathrm{CO}_{2}$ to reach dense phase, consistent with realistic pipeline specifications for transport and injection of the $\mathrm{CO}_{2}$ into deep geological formations. Whereas the base plant is defined by its operating capabilities (without CCS), the assessment of the capture and compression system, as well as the environmental impacts, require further details of the flue gas, in particular flow rate and chemical composition.

In 2013, the global generation of electricity from biomass reached $405 \mathrm{TWh}$, assuming an average capacity factor of over $50 \%\left[{ }^{1}\right]$. This corresponds to $1.75 \%$ of the global electricity production (i.e. 23.127 PWh in 2013, $\left.\left[{ }^{2}\right]\right)$. Today, most biopower plants are fairly small units, usually in the tens of $\mathrm{MW}_{\mathrm{e}}$, ranging typically from 1 to $100 \mathrm{MW}_{\mathrm{e}}$. The small size is mainly due to limited availability of local feedstock combined with high transportation cost $\left[{ }^{3}\right]$. For this reason, biopower plants are often deployed in geographical areas with substantial biomass crops, aimed at harnessing biomass sustainably at a rate consistent with natural growth.

Negative emissions, resulting from the combining of bioenergy with carbon dioxide capture and storage (BECCS), have become an issue of growing interest. According to the $5^{\text {th }}$ assessment report of the IPCC (Working Group 3), about half of the scenarios needed to limit the atmospheric concentration of greenhouse gases at $430-480$ ppm $\mathrm{CO}_{2}$ equivalents feature BECCS. As these options jointly account for more than $5 \%$ of the global primary energy supply $\left[{ }^{4}\right]$, it is necessary to further assess the potential for $\mathrm{CO}_{2}$ mitigation from a systemic perspective. Essential components are, on the one hand, the localisation and size of the plant vis-à-vis the biomass feedstock, the possible grid connection, and, on the other hand, life-cycle emissions. Relevant studies must be case specific, mainly conducted from the perspective of biomass (availability and inherent properties), as well as technology selection pursuant to local and regional demand for electricity combined with affordable pricing, and, last but not least, opportunities for $\mathrm{CO}_{2}$ storage. In this respect, it must be recognised that biomass sources are often located far from plausible storage sites $\left[{ }^{5}\right]$.

As no BECCS demonstration project has been realised so far (confer GCCSI database $\left[{ }^{6}\right]$ ), relevant studies anywhere in the world are based on assumptions or experiences from related projects $\left[{ }^{5}\right]$. Without CCS, typical parameters of a high-pressure and high-performance biopower plant converting agricultural residues may be as high as $88-90 / 535-540\left(\mathrm{bar} /{ }^{\circ} \mathrm{C}\right)$, reaching a plant efficiency up to $32 \%$ (LHV) (cf. Figure 1, left). The given steam parameters are taken as the upper limits of efficiency used in the parametric study. Likewise, a medium-pressure and medium-performance plant, with steam parameters of $49 / 450$ (bar $/{ }^{\circ} \mathrm{C}$ ), may reach typically $27 \%$ efficiency (LHV) provided the same feedstock $\left[{ }^{7}\right]$.

Today, $600-800 \mathrm{MW}_{\mathrm{e}}$ has become a common unit size for modern coal power plants (e.g. in China) with efficiency typically around $44 \%$ (LHV) $\left[{ }^{8}\right]$. Even larger plants are built to benefit from the higher efficiency, for instance the $1070 \mathrm{MW}_{\mathrm{e}}$ Maasvlakte MPP3 power plant in the Netherlands, with $46 \%$ efficiency $\left[{ }^{9}\right]$. This plant, fuelled essentially with coal, is capable of receiving up to $30 \%$ biomass. The plant became operational in 2015, ready to be swiftly retrofitted with CCS, subject to commercial decision (cf. the Dutch ROAD project, Rotterdam Opslag en Afvang Demonstratieproject $\left[{ }^{10}\right]$ ). If realised, $90 \%$ of the $\mathrm{CO}_{2}$ will be captured from a slip stream of flue gas equivalent to $250 \mathrm{MW}_{\mathrm{e}}$, and permanently stored in a depleted gas field off the coast of Rotterdam. 


\section{Co-firing biomass with coal}

Compliant with many hot geographical regions the utilisation of low-quality heat is prone to attract marginal interest, if any. Therefore, electricity-only conversion has been used in all cases considered in a parametric study.

In modern coal-fired power plants, co-firing with biomass offers a substantially higher net efficiency than is usually obtainable in dedicated biopower plants (cf. Figure 1, left). To the extent that coalfired power plants are readily available and operational, co-firing represents a true option. By replacing a portion of coal with biomass, co-firing seems to be the most economic near-term solution for employing biopower at large. In general, modern coal power plants can usually accept up to $15 \%$ biomass without modifying the steam boiler system (except for the solid-fuel feed system). Because the existing environmental control equipment can be used even at a higher percentage of biomass without major modifications, co-firing is a far less expensive option than building a new biopower plant on a green field $[3]$.

If for instance a modern $660 \mathrm{MW}_{\mathrm{e}}$ pulverised-coal power plant is at hand, it makes probably more sense to apply co-firing with $15 \%$ biomass, than building an entirely new biopower plant in the 100 $\mathrm{MW}_{\mathrm{e}}$ class to make use of the available biomass. The former will also generate more electric energy from the biomass. If both plants include CCS, the difference becomes even more pronounced, simply because the BECCS will sacrifice far more power on relative terms. The implication is that the BECCS alternative offers significantly less net electric energy to the grid.

Fuel flexibility implies i.a. that the plant can be adjusted to make use of different fuels in a way that ensures optimal performance, even with co-firing. Compared with the amount of replaced coal, biomass will contribute to reducing the amounts of sulphur dioxide $\left(\mathrm{SO}_{2}\right)$, nitrogen oxides $\left(\mathrm{NO}_{\mathrm{x}}\right)$, and other emissions. In this way, co-firing allows the biomass to be converted to electricity with low local pollution whilst benefitting from the elevated efficiency of modern coal power plants. Thus, adding biomass to the coal is considered an effective greening measure. After adjusting the boiler for peak performance, little or no loss in efficiency will occur by feeding moderate amounts of biomass to the coal $\left[{ }^{11}\right]$. This is generally referred to as fuel flexibility. Co-firing also offers options for CCS, thus reducing the overall emission of $\mathrm{CO}_{2}$ by typically up to $90 \%$ with an efficiency penalty of roughly $10 \%$ points (cf. Figure 1, taking the difference between the left-hand and the right-hand trajectories).

Figure 1: Trajectories of biopower plant net efficiency without CCS (left), and the resulting net efficiency of co-fired biomass and biopower with CCS (BECCS, right) depending on plant size (net power output)

\section{BECCS}

Conceptually, biopower systems may employ either of the following primary conversion principles: direct-firing, co-firing, gasification, pyrolysis and anaerobic digestion of biomass $\left[{ }^{12}\right]$. These principles align with the major concepts for $\mathrm{CO}_{2}$ capture of bioenergy solutions (BECCS): pre-combustion, oxycombustion, and post-combustion. Whereas the former concept involves gasification (and/or 
pyrolysis), concepts for oxy-combustion and post-combustion $\mathrm{CO}_{2}$ capture (i.e. flue gas scrubbing) are relevant for the remaining conversion principles.

The efficiency of basic biopower plants disposing of large amounts of agricultural residues is usually around 30\% (LHV), depending on technology and plant size. With high-quality wood chips one may consider advanced biopower in hundreds of $\mathrm{MW}_{\mathrm{e}}$. If electricity is the only yield, such units may exceed $40 \%$ efficiency (LHV) [ $\left.{ }^{3}\right]$. However, at this high efficiency level capital expenses are likely to become prohibitive. Therefore, in order to cut cost, an efficiency level well below $40 \%$ seems viable, although the availability of suitable high-quality wood chips within a reasonable distance from the plant appears to be a limiting factor. Assume for instance a $800 \mathrm{MW}_{\mathrm{e}}$ biopower plant with $40 \%$ efficiency: in order for such a plant to operate at full capacity, over 500 tonne biomass must be provided each hour ${ }^{1}$. This is equivalent to 17 lorries per hour carrying 30 tonne each. Aggregated over the year, almost 150000 deliveries of biomass would be required.

As this example signifies a logistical challenge, a more realistic approach is to assess the size of biopower from a perspective of dedicated biopower units, viable in a range from roughly 25 to 100 $\mathrm{MW}_{\mathrm{e}}$. In contrast, coal-fired power plants for optional co-firing of biomass are significantly larger (i.e. 600-800 $\mathrm{MW}_{\mathrm{e}}$ ). Depending on the rate of biomass-firing, the dedicated biopower plant and the cofired plant can handle essentially the same amount of biomass.

Figure 2: Generalised flow sheet of a BECCS system (left) and a coal power plant suitable for co-firing with biomass (right)

Figure 1 depicts the generalised concepts for the BECCS system (left) and for the co-fired power system (right), as used to form the cases of the present study. Although these power cycles appear rather similar with the same type of flue-gas scrubbing, they will generally differ significantly in size, performance, complexity and technical solutions. Due to inadequate technology and lacking economic assessments, the cost of BECCS is not well understood []$\left.^{5}\right]^{2}$.

\section{Method}

The study is intended for screening the potentiality of surplus biomass sources comprising agricultural residues for electricity provision with negative $\mathrm{CO}_{2}$ emission. The research question is how these sources can be best used to provide clean electric energy. Responding to this question, emphasis has been placed on the impact of converting the biomass either in dedicated plants (biopower and BECCS) or co-fired with coal in larger plants (without and with CCS).

In the study, viable efficiencies and other operational specificities are used in the assessment of BECCS and co-firing plants retrofitted with CCS. The study does not present any specific design,

\footnotetext{
${ }^{1}$ Dry biomass from rice straw with $\left[\mathrm{C}, \mathrm{H}, \mathrm{O}, \mathrm{N}, \mathrm{S}\right.$, moisture, ash, $\left.\mathrm{CO}_{2}\right]=[0.3888,0.0476,0.3551,0.0052,0.0005,0.0000,0.2028,0.0000]$ resulting in a lower heating value of $14.137 \mathrm{MJ} / \mathrm{kg}$

${ }^{2}$ The cost of biopower varies widely because of the many feedstocks and processes. The cost will vary even more when it comes to BECCS, because CCS will have a significant implact on the cost of electricity $\left[{ }^{3},{ }^{5}\right]$. Co-firing biomass with coal in larger plants, however, implies a rather limited incremental cost provided CCS is already included.
} 
although key components of a full CCS chain have been embedded, including the interaction with the steam cycle.

Three trajectories have been selected for net electric efficiency of the basic biopower plant used in the study, notably low, medium, and high. The basic plants operate without CCS, fuelled with agricultural residues. When adding CCS to these plants, the net power output will drop significantly because of the energy penalty inherent to the integration of CCS. Although a larger BECCS can be considered, its size is likely to fit to the regional supply of biomass and the desired timewise availability of the plant.

Furthermore, the parametric study is based on assumptions typical of relevant steam cycles. Hence, a subset of performance characteristics has been chosen, such as fuel composition, the plant's net efficiency and the net generated power (without CCS), capture rate, condenser pressure etc. constituting the input to a proprietary computational model (cf. Table 1). The method is further based on a complete reaction model, using fuel compositions and plant performance characteristics, as briefly outlined below.

\section{Computer modelling}

In principle the computer modelling includes the following stages:

1) Biomass is mixed with reference coal at a desired percentage, thus defining the common fuel composition. On this basis, the computer model provides the resulting performance data for the co-firing scheme, including flue gas composition and fuel demands.

2) The mixed fuel is then decomposed into coal and biomass by superpositioning, and the alternative usage of the biomass fraction is re-assessed according to a BECCS configuration on the basis of the biomass feedstock alone, providing for each case the resulting performance data, flue gas composition and fuel demand.

3) Then the impacts of biomass usage are compared quantitively, and subjected to scrutiny.

Table 1: Parameters and resulting performance data pertaining to the computer modelling

\section{Biomass feedstock}

For industrial players, the security of fuel supply is an important issue, especially if the feed rate of the plant exceeds the regional biomass sources. This probably explains why biopower plants usually are less than a tenth of the size of modern coal power plants. It seems obvious that in deploying biopower plants, the size and efficiency are likely to depend on the quality and availability of biomass along with the harvesting and seasonal variation, and also the means for feedstock supply. This is more than a cost issue, it also constitutes a logistic challenge. Therefore, in order to justify investments and stable operations of larger biopower units, alternative fuels may be required. This calls for comparative assessment of biopower and optional co-firing, especially in systems that employ CCS. 
In order to secure the required supply of electricity by larger biopower units optional fuels are required - mainly lignite and coal, and in some cases even peat. Likewise, many coal-fired power plants allow for co-firing with biomass to significantly reduce emissions, especially greenhouse gases, particulates and sulphur dioxide. From this perspective, comparing impacts of biopower makes sense whether the biomass is converted in dedicated plants (BECCS) or in CCS-based coal power plants via co-firing. In general, the latter option offers a considerably higher efficiency and, hence, a greater climate-mitigation potential.

The present analyses are applied to selected feedstocks of agricultural residues typical of Indonesia. The biomass is converted either in existing large-scale coal power plants available for co-firing or in smaller decentralised BECCS. Recent studies carried out by the GIZ (Conrad \& Prasetyaning, 2014) $\left[{ }^{13}\right]$ conclude that residues of oil palm, rice paddy and sugar cane are the predominant resources of bioenergy feedstock in Indonesia due to the large volume of crops production $\left[{ }^{14}, 15,16,17,17\right]$.

The key combustion characteristics of the various types of biomass are summarised in Table 2, specified through proximate and ultimate analyses.

Table 2: Combustion characteristics and feedstock compositions of biomass sources of Indonesia (

For comparison, the compositions of fuels used in this study (rice straw and palm kernel shell), and the reference coal (Pittsburgh No. 8) are presented in Table 3.

Table 3: Fuel characteristics of Indonesian palm kernel shell and a reference coal (Pittsburgh No. 8)

Although the humidity of the biomass has not been given, it is considered rather low in a dry country like Indonesia. Therefore, the impact of humidity in the present cases is considered to mainly affect the water dew point and to some extent the acid dew point. For instance, with $25 \%$ co-firing in a basic $660 \mathrm{MW}_{\mathrm{e}}$ coal power plant with 38\% efficiency and $90 \%$ capture rate, the efficiency will drop rather marginally from 27.76 to $27.74 \%$ if the water content of the biomass is raised from 0 to $20 \%$, and the water dew point of the emitted flue gas will increase from 40.4 to $41.6^{\circ} \mathrm{C}$. Likewise, if a biopower plant of $100 \mathrm{MW}_{\mathrm{e}}$ and $32 \%$ efficiency is equipped with CCS (i.e. BECCS) the corresponding efficiencies will drop from 20.9 to $20.4 \%$ provided the water content of the biomass goes from 0 to $20 \%$, and the water dew point of the flue gas in the stack will increase from 47 to $54^{\circ} \mathrm{C}$.

The variation in main reactive properties of these fuels (i.e. the mass fraction of hydrogen and oxygen over the content of carbon) appears from the van Krevelen diagrammes shown in Figure 3, thus identifying the main characteristics of the fuels. 
Figure 3: Main characteristics expressed by mass fraction of hydrogen $(\mathrm{H})$ and oxygen contents $(\mathrm{O})$ over carbon content (C) in Indonesian rice straw (left), palm kernel shell (middle), and the reference bituminous coal (Pittsburg No. 8, right).

\section{Power plant assumptions}

Assessments are based on key parameters of independent biomass-fired power plants and co-firing of biomass in conventional coal power plants comparable to the current Indonesian situation. Indonesia was selected mainly for three reasons, a) because of abundant amounts of agricultural residues, b) because Indonesia is in need of electricity rather than space heating, and c) co-authors (at IIASA) are engaged with Indonesia via projects identifying the potential of land use and biomass sources. The efficiency of biopower plants forming the basis for BECCS has been selected to comply with three efficiency trajectories (low, medium and high), essentially corresponding to four classes of biopower capacity: 25, 50, 75 and $100 \mathrm{MW}_{\mathrm{e}}$ (cf. Table 4).

As can be immediately concluded, the viability of CCS is hard to justify for small sized plants, like BECCS. The justification may become easier as the plant becomes significantly larger and more efficient, thus implying optional co-firing with CCS. Co-firing may also offer a higher availability of the plant ( $85 \%$ or more), as coal is a commercial commodity supplied from multiple sources.

Table 4: Selected levels of electricity yield and net efficiency for the basic biopower plants (operating without CCS)

For the co-firing alternative, a conventional $660 \mathrm{MW}_{\mathrm{e}}$ coal power plant with an initial efficiency of $38 \%$ (LHV) has been chosen as base case (i.e. sub-critical steam conditions). A generic bituminous coal (Pittsburgh No.8) is used for co-firing with biomass, first with rice straw, then with palm kernel shell. It is assumed that up to $25 \%$ biomass can be co-fired without essential modifications of the plant. The condenser pressure is assumed to be similar for the BECCS and the alternative coal power plant, as air cooling towers are used for both (i.e. 0.003 bar, $36^{\circ} \mathrm{C}$ ). The flue gas is cleaned via an absorption process using an amine-based solvent requiring $3.24 \mathrm{GJ}$ heat per tonne $\mathrm{CO}_{2}$ to be regenerated. For both alternatives, this heat is provided by steam extracted from the mediumpressure turbine at 5 bar and $160^{\circ} \mathrm{C}$. In the study, the captured $\mathrm{CO}_{2}$ is compressed to meet a pipeline pressure of 146 bar for delivery in dense phase.

The estimation of the coal power plant is made on the assumption that the plant is fully equipped with environmental control systems (ECS) removing $99 \%$ of the sulphur contained in the flue gas, whereas the BECCS alternative is without ECS. The calculations are further based on ISO conditions.

Moreover, in co-firing mode, the biomass will benefit from the environmental control system already in place, dealing also with $\mathrm{NO}_{\mathrm{x}}$. With biopower and BECCS, however, no specific environmental control device has been considered in the study. NOx emissions are usually reduced either by combustion control measures avoiding or reducing NOx formation, or by flue gas treatment (or combined $)^{3}\left[{ }^{18},{ }^{19}\right]$.

\footnotetext{
${ }^{3}$ A typical consequence of co-firing is a modest reduction of boiler efficiency, which may limit the economic value of biomass fuels. If NOx is to be removed from the flue gas, a dry system is likely to be preferred, either via selective catalytic reduction (SCR) or via selective non-
} 


\section{Combustion estimation}

The combustion estimation assumes steady state operation, converting the actual fuel. In co-firing mode, the fuel is composed of the fractions of coal and biomass mixed into a homogeneous fuel. Important input is the resulting net plant efficiency (without CCS) and standard operating conditions, including the required capture rate.

More specifically, a generic carbonaceous fuel is characterised by its chemical composition, made up by the mass fractions of carbon, hydrogen, oxygen, sulphur, nitrogen, water and ash, defined as follows $\left[{ }^{20},{ }^{21}\right]$ :

$$
\text { Carbonaceous fuel }=\mathrm{CH}_{\mathrm{a}} \mathrm{O}_{\mathrm{b}} \mathrm{S}_{\mathrm{c}} \mathrm{N}_{\mathrm{d}}+\left[\mathrm{eH}_{2} \mathrm{O}+\mathrm{Ash}\right]
$$

A balanced (complete) combustion reaction reads:

$$
\begin{aligned}
& \mathrm{CH}_{\mathrm{a}} \mathrm{O}_{\mathrm{b}} \mathrm{S}_{\mathrm{c}} \mathrm{N}_{\mathrm{d}}+\left[\mathrm{H}_{2} \mathrm{O}+\mathrm{Ash}\right]+v\left(\mathrm{O}_{2}+\mathrm{A} \mathrm{N}_{2}+\mathrm{B} \mathrm{Ar}+\mathrm{D} \mathrm{H}_{2} \mathrm{O}\right) \rightarrow \\
& \mathrm{CO}_{2}+\mathrm{y} \mathrm{O}_{2}+\mathrm{cSO}_{2}+\left(\frac{\mathrm{d}}{2}+v \times \mathrm{A}\right) \mathrm{N}_{2}+v \times \mathrm{BAr}+\left[\frac{\mathrm{a}}{2}+(\mathrm{e}+v \times \mathrm{D})\right] \mathrm{H}_{2} \mathrm{O}+[\text { Ash }]
\end{aligned}
$$

Excess oxygen $[\varepsilon]$ :

$$
\varepsilon=\frac{\mathrm{y}}{\sum \text { mol }_{\text {dry products }}}
$$

As equation 2 determines the reaction products per unit fuel, these products relate directly to the amount of fuel converted. Hence, they explicitly depend on the thermal efficiency of the plant. The required amount of fuel is

$$
\mathrm{m}_{\mathrm{F}}=\frac{\mathrm{P}_{\text {net }}}{\eta \mathrm{LHV}_{\mathrm{dry}}}
$$

Here, $\eta$ denotes the net thermal efficiency of the plant (i.e. fuel to net electricity), and LHV denotes the lower heating value. By solving the above equations (1-4), the composition of the raw flue gas is determined. From this, in the case of CCS, the capture plant is estimated, including the impact of extracted steam for solvent recovery, the required $\mathrm{CO}_{2}$ compression work, and hence the resulting net power output (as indicated in Table 1). Essential are the properties of the extracted steam and the heat demand for solvent recovery, the expansion line of the low-end steam turbine (after extraction), the condenser pressure, and the export properties of the dense $\mathrm{CO}_{2}$.

Additionally, superpositioning is applied to the impacts of biomass and coal, using their respective fuel compositions and the overall operational characteristics of the plant as obtained with the fuels combined. In this way, the effect of biomass has been estimated as a function of the rate of co-firing. The same amount of biomass has been assumed to be converted in a BECCS configuration, whereby the impacts of the emissions and net electric power and net electric energy are compared with those of the co-firing case.

catalytic reduction (SNCR). Whereas the former requires temperatures in the range from $160-600^{\circ} \mathrm{C}$ (depending on the catalyst), the noncatalytic reduction is based on ammonia or urea injection usually at the top section of the boiler, at a temperature in the range from typically $900-1050^{\circ} \mathrm{C}$. Both systems add operational costs, mainly because of catalyst decay (with the SCR) and the consumption of ammonia or urea (with SNCR). The impact on net power and efficiency, however, is considered to be low or marginal. 
The combustion is provided in the steam boiler with assumingly $5 \%$ excess oxygen. Estimations require complete reactions of the chemical components of the fuel (i.e. carbon, hydrogen, oxygen,

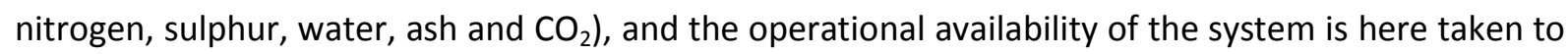
be $85 \%$.

Whereas the study is a case study, the model is generic, capable of considering any fossil fuel with the basic composition expressed above (i.e. Carbonaceous fuel $=\mathrm{CH}_{\mathrm{a}} \mathrm{O}_{\mathrm{b}} \mathrm{S}_{\mathrm{c}} \mathrm{N}_{\mathrm{d}}+\left[\mathrm{eH}_{2} \mathrm{O}+\mathrm{Ash}\right]$ ). This implies solid, liquid and gaseous fuels. The model also includes conventional air combustion and any oxidant that includes $\mathrm{O}_{2}, \mathrm{~N}_{2}$, $\mathrm{Ar}$ and $\mathrm{H}_{2} \mathrm{O}$ up to pure oxy-combustion. It also calculates the dew points for water and sulphur contained in the flue gas prior to and after $\mathrm{CO}_{2}$ removal.

\section{Energy penalty}

The net base-plant efficiency (prior to $\mathrm{CCS}$ ) and the rate of $\mathrm{CO}_{2}$ capture have been used as parameters characterising the fully integrated CCS-based power cycle. However, in systems employing absorption techniques, a significant amount of heat is sacrificed in order to recover the solvent. This heat is provided by steam extracted from the steam turbine, usually around 3-5 bar, depending on the solvent. This implies that the power output of the tail-end turbine will decrease due to reduced steam flow.

The amount of heat required by the reboiler system, including inherent heat losses, is estimated from the given amount of $\mathrm{CO}_{2}$ to be removed, provided the solvent is taken into account, characterised in $\mathrm{GJ} / \mathrm{t} \mathrm{CO} \mathrm{CO}_{2}$ (or similar). The steam needed for the recovery of solvents is then estimated based on the pressure and temperature of the extracted steam, internal pressure loss in the transfer pipe diverting the steam from the turbine house to the reboiler, and the main condenser pressure. In order to carry out this calculation, the isentropic efficiency of the steam turbine section, between the extraction point and the condenser, is used to define the expansion line and, hence, the enthalpy and entropy of the steam at both points. As steam extraction implies lost power generation, reboiling of the solvent represents a significant part of the energy penalty.

Another substantial part of the energy penalty is compression work required to bring $\mathrm{CO}_{2}$ from ambient pressure to dense phase. This transformation requires multistage compression of wet and dry $\mathrm{CO}_{2}$, and the required power depends on compressor design and the availability of external cooling sources (water or air). Energy is sacrificed if additional fans or pumps are required; this being more pronounced in oxy-combustion schemes, however.

\section{Systemic impacts}

The systemic impacts assessed in the case studies are listed in Table 5, resulting mainly from the computer modelling (cf. Table 1) and from the defined cases, prior to and after CCS integration.

Table 5: Systemic impacts pertaining to the case studies 


\section{Main findings}

A summary of the main findings relating to the impact of biomass is presented in Table 6, giving the core characteristics of four cases: two cases using rice straw (co-fired with bituminous coal and in BECCS configuration) and two similar cases using palm kernel shell.

Table 6 presents eight cases, whereof four cases refer to operations prior to CCS integration and the remaining four cases to operations with CCS. Half of the cases are co-fired (with and without CCS), and the other half uses dedicated biopower (with and without CCS). Each case is based on a reference feed rate of biomass (i.e. $9.308 \mathrm{~kg} / \mathrm{s}$ ).

\section{Base-plant operations prior to CCS integration}

- If converted in a basic co-firing plant at 38\% efficiency (prior to CCS integration), the feed rate of rice straw will contribute $50 \mathrm{MW}$ net electricity.

- In co-firing mode, the fraction of co-fired biomass is $13.273 \%$.

- The remaining fraction of reference coal will be $86.727 \%$, which is accountable for $610 \mathrm{MW}_{\mathrm{e}}$, thus supplying jointly $660 \mathrm{MWe}$ to the grid.

- If a similar amount of rice straw is converted in a basic biopower plant (without CCS) the resulting net power will be only $36.845 \mathrm{MW}_{\mathrm{e}}$, due to the lower efficiency (28\% LHV).

- In the basic biopower configuration, biomass is the only feedstock, i.e. $100 \%$.

- Operations with palm kernel shell are almost similar.

\section{Operations after CCS integration}

- The impact of CCS integration and the selected feed rate of biomass on net electric contributions will change significantly.

- In co-firing mode,

$\circ$ the net efficiency drops from 38 to $28.74 \%$ (LHV),

$\circ$ the resulting net power account for the biomass changes from initially 50 to 37.81 $\mathrm{MW}_{\mathrm{e}}$.

○ The feed rate of biomass is still $13.273 \%$.

- Further information can be derived: $86.727 \%$ of the feed is coal, and coal is now accountable for $461.36 \mathrm{MW}_{\mathrm{e}}$, thus supplying jointly $499.26 \mathrm{MW}_{\mathrm{e}}$ to the grid.

- For the BECCS alternative,

$\circ$ the net efficiency drops from 28 to $17.81 \%$ (LHV), and

$\circ$ the resulting net power is $23.433 \mathrm{MW}_{\mathrm{e}}$, only $62 \%$ of what is obtainable with the retrofitted co-firing plant.

- The other two cases, based on palm kernel shell, show roughly the same results, however, with slightly different values.

The flue gas composition for these cases is listed in the Table 6, before and after CCS integration, including the dew points. One should keep in mind that for the co-firing alternatives, the flue gas compositions (within the black fields) are theortical, referring to the fractions of co-fired biomass only, and they are not measurable in situ. Compositions that can be measured for these configurations are presented in Table 7. 
Table 6: The concentration of the chemical components resulting from rice straw and palm kernel shell, either co-fired with bituminous coal or converted in dedicated BECCS plants using the same amount of biomass $(9.308 \mathrm{~kg} / \mathrm{s})$. For the cofiring alternatives, compositions within the black fields refer to the fraction of co-fired biomass only, and are not measurable at the plant.

Here, the acid dew points are calculated according to two different approaches, one by Okke, the other by Verhoff $\left.{ }^{22}\right]$. Particular interest is paid to the specific impacts on the operational capacities, such as a) net power, b) efficiency penalty, c) fuel properties, d) amounts of $\mathrm{CO}_{2}$ formation, e) neutral and negative $\mathrm{CO}_{2}$ emissions, and $\mathrm{f}$ ) the relevance of initial efficiency and performance. These impacts are further addressed in the following subsections.

\section{Net power}

Figure 4 presents the net power output of the optional plants as a function of the biomass demand (i.e. the feed rate of biomass) and underpins the advantage of higher initial efficiencies, which usually relate to the size of the plant and its intended operational availability.

Figure 4: Impact of biomass on the net power output depending on technology (BECCS and co-firing with coal) as a function of the feed rate of biomass. Rice straw alternative (left) and palm kernel shell (right).

As shown, the difference between the rice-straw case and the palm-kernel case appears as being rather minor although it will increase as the biomass demand grows.

\section{Efficiency penalty}

The study shows that by introducing CCS with typically $90 \%$ capture rate the power generation efficiency will drop by roughly $10 \%$-points. In the $50 \mathrm{MW}_{\mathrm{e}}$ class, the efficiency penalty is estimated to be $10.19 \%$-points of the BECCS case with rice straw and 10.87\%-points with palm kernel shell with the same feed rate $\left(9.3 \mathrm{~kg} / \mathrm{s}\right.$ biomass), offering $31.8 \mathrm{MW}_{\mathrm{e}}$ and $30.59 \mathrm{MW}_{\mathrm{e}}$ respectively. The difference refers essentially to the amounts of $\mathrm{CO}_{2}$ formed, as the $\mathrm{CO}_{2}$ must be isolated, purified and compressed. With co-firing, however, the efficiency penalty at an equivalent amount of biomass (around $30 \mathrm{MW}_{\mathrm{e}}$ ) is somewhat lower, as shown in Figure 5. Mainly because of the more efficient conversion of the mixed fuel, the efficiency penalty is estimated to be $9.26 \%$-points and $9.32 \%$-points respectively with the same feed rate of biomass $\left(9.3 \mathrm{~kg} / \mathrm{s}, 31.8 \mathrm{MW}_{\mathrm{e}}\right.$ and $\left.30.59 \mathrm{MW}_{\mathrm{e}}\right)$. Although the plant generates almost $500 \mathrm{MW}_{\mathrm{e}}$ net electric power (i.e. 499 and $498 \mathrm{MW}_{\mathrm{e}}$ ), $70.1 \mathrm{MW}_{\mathrm{e}}$ relates to the rice straw case and $69.7 \mathrm{MW}_{\mathrm{e}}$ relates to the palm kernel shell case. 
Figure 5: Efficiency penalty as a function of the rate of co-firing with biomass in a coal power plant (660 MWe base-plant size prior to retrofitting with CCS)

The implication is that the resulting net efficiency with CCS is affected mainly by the base-plant efficiency, and only marginally by the size of the plant.

\section{Fuel properties}

In co-fired systems, the reactive properties of the resulting fuel will be affected depending on the feed rate of biomass. However, with smaller amounts of biomass the impacts will be rather small. Most significant are the contents of carbon, hydrogen and oxygen. For systems considered in this study, the predominant characteristics of fuel composition are presented in Figure 6 . The graphs suggest that with a co-firing rate up to roughly $35 \%$ biomass, the resulting fuel mixture remains bituminous.

The implication is that by adding up to $30 \%$ biomass to the reference coal, the characteristics of the mixed fuel will not be essentially changed. However, by adding larger amounts of biomass, the predominant fuel characteristics will shift towards the characteristics typical of lignite. Hence, the operational conditions may have a significant bearing on the boiler system. According to the main findings of the study, as suggested in the graphs in Figure 6, co-firing with biomass up to $20-25 \%$ is expected to have only marginal impacts. It is assumed that this feed rate of biomass can be handled without extensive redesign of the boiler system. With larger amounts of biomass, however, this may affect either the boiler design, the mode of operations, or both combined.

Figure 6: Impact of mixing biomass with coal on resulting feed composition according to classical typology for coal. Marked symbols on the graphs signify increments of $10 \%$ additional biomass from one symbol to another, starting at zero with plain coal (i.e. Pittsburgh No.8, no difference), ending at $100 \%$ pure rice straw and palm kernel shell, respectively.

\section{$\mathrm{CO}_{2}$ formation}

The amounts of net carbon dioxide emissions resulting from rice straw and palm kernel shell are shown in Figure 7 as a function of the biomass feed rate.

Figure 7: Impact of biomass on the amount of $\mathrm{CO}_{2}$ emitted depending on technology (BECCS and co-firing with coal) as a function of the feed rate of biomass. Rice straw alternative (left) and palm kernel shell (right).

For comparison, the impact of the combined fuel (i.e. biomass co-fired with bituminous coal), is presented in Table 7, estimated on operational conditions similar to those of Table 6. The difference is that here the actual flue gas composition is considered, whereas Table 6 presents the theoretical flue gas composition that results from the biomass in isolation, thus excluding the impact of the coal. 
Hence, Table 7 presents the flue gas compositions that can be recorded (prior to and after absorption).

Table 7: Combined impact on the actual and measurable flue gas compositions from the $660 \mathrm{MW}_{\mathrm{e}}$ co-fired plant with $9.308 \mathrm{~kg} / \mathrm{s}$ biomass (formed and emitted)

\section{Neutral and negative $\mathrm{CO}_{2}$ emissions}

The term "carbon-negative" relates to measures permanently removing $\mathrm{CO}_{2}$ from the natural carbon cycle. Such measures include bioenergy with CCS, biochar stored in the soil ${ }^{4}$, and direct $\mathrm{CO}_{2}$ capture from the ambient air, provided sustainable harvesting of the biomass. The resulting $\mathrm{CO}_{2}$ will either add to the atmosphere, or be considered neutral or negative, depending on origin of the carbonaceous feedstock and the final destination of the $\mathrm{CO}_{2}$ (i.e. whether it is released to, or prevented from entering, the surrounding air). To the extent that $\mathrm{CO}_{2}$, formed by biomass conversion, reenters the natural carbon cycle, bio power is considered $\mathrm{CO}_{2}$-neutral (due to photo synthesis). Moreover, as the $\mathrm{CO}_{2}$ emitted from bioenergy systems is by definition carbon neutral, systems combining bio power and CCS go one step further by capturing and storing "neutral" $\mathrm{CO}_{2}$. The flow of $\mathrm{CO}_{2}$ which has been permanently stored is taken to be carbon negative because it is removed from the atmosphere. In contrast, $\mathrm{CO}_{2}$ resulting from coal combustion will either add to the atmosphere if emitted, or it becomes neutral if captured and stored.

Accordingly, the trajectories of Figure 7, originating from the biomass, illustrate the amount of $\mathrm{CO}_{2}$ released to the atmosphere as neutral $\mathrm{CO}_{2}$. As $90 \%$ capture rate was selected for the case study, $90 \%$ of the $\mathrm{CO}_{2}$ produced from the biomass will become carbon negative emissions, whereas the remaining $10 \% \mathrm{CO}_{2}$ is released to the atmosphere as carbon neutral emissions. Table 8 summarises the amounts of the neutral and negative $\mathrm{CO}_{2}$ emissions.

Table 8: Amounts of $\mathrm{CO}_{2}$ emitted and stored, termed "neutral" and "carbon negative", originating from the actual biomass. The co-firing alternatives refer to the impact of biomass only. All cases are based on the same amounts of biomass feedstock $(9.308 \mathrm{~kg} / \mathrm{s})$.

\section{Relevance of base-plant efficiency}

With reference to the net electric energy supplied to the grid (GWh), the neutral and negative emissions from the BECCS plants will be higher than those resulting from the same amount of biomass converted in a very large power plant equipped with CCS, where the biomass is co-fired with coal. The reason is that the efficiency of the co-firing and the BECCS options differs from the largest

\footnotetext{
${ }^{4}$ If biomass is transformed into stable carbonaceous biochar structures and stored for hundreds and even thousands of years in the soil, biochar systems are deemed carbon negative; this implies a net reduction of $\mathrm{CO}_{2}$ in the atmosphere. Depositing biochar the soil offers other related benefits, such as soil fertility and microbial life lowering the need for chemical fertilisers, less emissions of nitrous oxides $\left(\mathrm{N}_{2} \mathrm{O}\right)$ and emissions from agricultural and forestry waste $\left(\mathrm{CO}_{2}\right.$ and $\left.\mathrm{CH}_{4}\right)$. However, if the biochar is combusted (or oxidised), it can only be considered carbon negative if the $\mathrm{CO}_{2}$ resulting from the usage is captured and permanently stored.
} 
and presumably the most efficient BECCS plant $\left(100 \mathrm{MW}_{\mathrm{e}}\right)$ to the smaller and less efficient BECCS plant (say $10 \mathrm{MW}_{\mathrm{e}}$ ), as indicated in Table 9.

Table 9: Comparing feed rate characteristics of the co-firing and BECCS alternatives with large feed rates (of rice straw), high BECCS efficiency, and lower feed rates (of rice straw), lower BECCS efficiency, comparing the impact of similar feed rates for the two cases

This also implies that these BECCS alternatives require more biomass to provide the same amount of electric energy. Hence, as the amount of $\mathrm{CO}_{2}$ is proportional to the amount of feedstock used, more $\mathrm{CO}_{2}$ will be formed, captured and stored than would be the case with the biomass in the co-firing cases. Estimates indicate that the additional biomass demand will range from $31 \%$ to $94 \%$ in the BECCS case (using rice straw) as compared to the co-firing case assuming similar fuel and feed rates. Here the BECCS cases, considered at the lower end of the power range $\left(10 \mathrm{MW}_{\mathrm{e}}\right)$ and at the upper end (100 MWe $)$, are estimated at efficiencies of $25 \%$ and $32 \%$ (LHV) respectively. In the co-firing case, conversion of the biomass takes place in a large coal power plant operating at $660 \mathrm{MW}_{\mathrm{e}}$ and $38 \%$ efficiency (LHV) in basic mode (without CCS).

The estimates of Table 9 are only indicative, as they may change subject to plant size and operating capabilities. They may explain, however, why the initial efficiency of a power plant is crucial when considering the retrofitting of an existing coal power plant with CCS, or the planning of a new BECCS.

\section{Conclusions}

Conclusions are drawn from specific case studies of biomass conversion in dedicated biopower plants equipped with CCS (BECCS), or in larger co-fired plants retrofitted with CCS for the purpose of generating negative $\mathrm{CO}_{2}$-emissions. The results reveal significant advantages of co-firing schemes as compared to independent BECCS plants.

Provided that an operational coal power plant equipped with CCS is at hand, more net electric energy can be provided from co-firing the biomass with coal than by converting the biomass in a dedicated BECCS plant, although the amount of $\mathrm{CO}_{2}$ captured, stored and released per unit biomass is identical. The implication is that in order to provide the same amount of net electric energy from biomass converted in an independent BECCS plant or via co-firing with coal in a larger plant retrofitted with CCS, the BECCS plant must burn roughly $30-90 \%$ more biomass and will generate a corresponding amount of additional $\mathrm{CO}_{2}$ (dependent on the size and complexity of the plant).

The significant efficiency penalty with CCS makes efficiency a critical parameter in the consideration of BECCS. It seems evident that without a high initial efficiency of the basic biopower plant prior to CCS integration, BECCS will hardly become commercially viable, due to limited amounts of electricity to sell. Most likely, a sufficiently high net efficiency can only be ensured in large plants with advanced steam parameters (i.e. super-critical steam power cycles).

When it comes to safeguarding local or regional energy supply, which is important in countries with power scarcity, the use of available biomass sources seems preferable for co-firing in existing coal 
power plants. In the context of Indonesia, with vast amounts of agricultural residues, distributed biopower is seen as an attractive option, backed by resource availability and the need for electrification. Developing scenarios should include studies on retrofitting existing plants with CCS, and the optional building of entirely new co-fired power plants and dedicated BECCS. As larger BECCS plants require extensive volumes of biomass and stable supply throughout the year, logistics may become a determining factor.

The above insights should lead to further investigations, especially as concerns the impacts of negative emission on commercial and societal terms. This will include cost-benefit analyses pertaining to electricity tariffs and carbon pricing within a limited national context. Studies must further address the selection of technology, plant size, market opportunities and location vis-à-vis biomass sources, grid connection and last, but not least, the availability of storage sites for the $\mathrm{CO}_{2}$. Such analyses will be useful for the identification of patterns maximising the impacts of carbonnegative emissions.

\section{Acknowledgements}

This study has been funded partially by the authours' institutions.

\section{References}

\section{RENEWABLES 2014 GLOBAL STATUS REPORT}

BP statistical review of world energy 2014

IEA Energy Technology Essentials, ETE03. January 2007.

4 Fuss, S., Canadell, J. G., Peters, G. P., Tavoni, M., Andrew, R. M., Ciais, P., Yamagata, Y.: Betting on negative emissions. Nature Climate Change, 4(10) 2014, 850-853. (Retrieved from http://dx.doi.org/10.1038/nclimate2392)

5 Status and prospects of BIO-CCS. Key massages on BIO-CCS technology as option in a low carbon future. European Technology Platform for Zero Emission Fossil Fuel Power Plants, December 2015

6 Large Scale CCS Projects, the Global CCS Institute. Database available on www.globalccsinstitute.com/projects/largescale-ccs-projects\#map

7 Brendstrup, A.: Lesson Learned from High Efficiency Biomass Power Plants in China, Clean Tech, April 2012, Available on www.npti.in/Download/Renewable/POWERGEN\%20PRSTN_Renewable\%20April2012/High\%20 Efficiency\%20Biomass\%20Power\%20Plants\%20in\%20China.pdf (last visited August 2015)

8 Hetland, J.; LIU L.: Retrofitting with CCS: Options for the inventory of modern Chinese coal power plants. ICAE 2013, Pretoria, South Africa, 1-4 July 2013

9 MPP3 Maasvlakte. Available on vimeo.com/38169239 (last visited December 2015)

10 ROAD CCS, $\mathrm{CO}_{2}$ Capture. Available on road2020.nl/en/ccs-technologie/co2-afvang/ (last visited December 2015)

11 Hetland, J.; Barnett, J.; Read, A.; Zapatero, J.; Veltin, J.: $\mathrm{CO}_{2}$ transport systems development: Status of three large European CCS demonstration projects with EEPR funding. GHGT-12, Austin Texas, USA. 5-9 October 2014

12 Biopower. Presented in Renewable Energy World. Com 28 October 2014 (http://www.renewableenergyworld.com/rea/tech/bioenergy/biopower, last visited September 2015)

13 Conrad, Lisa, and Ikke Prasetyaning: Promotion of Least Cost Renewable in Indonesia. Deutsche Gesellschaft für Internationale Zusammenarbeit GmbH (GIZ), April 2014. (Cf. http://Icoreindonesia.or.id/downloads/overview_biomass_study_LCORE_FIN_withcover_smallsize.pdf, last visited in September 2015)

14 Idris, S., Rahman, N., \& Ismail, K.: Combustion characteristics of Malaysian oil palm biomass, sub-bituminous coal and their respective blends via thermogravimetric analysis (TGA). Bioresource Technology, 581-591, 2012.

15 Jenkins, B., Baxter, L., Miles, T., \& Miles, T. (n.d.): Combustion properties of biomass. Fuel Processing Technology, 54, 1998, 17-46. (http://dx.doi.org/10.1016/S0378-3820(97)00059-3)

16 Hassuani, S.: Biomass power generation sugar cane bagasse and trash. Piracicaba: CTC. 2005

17 Jenkins, B.M. and Ebeling, J.M.: Thermochemical properties of biomass fuels. California Agriculture 39(5,6), 1985, 14-16.

18 NOx control for coal-fired plant. IEA Clean Coal Centre, PF 09-13, November 2009

19 The SNCR option for large coal boilers. Power Engineering International, 01/02/2013 
20 Hetland, J: Water balance in oxy-combustion compared with post-combustion schemes, GHGT-11, Kyoto, Japan, 20-22 November 2012

21 Hetland, J: Flue gas processing: Strategies for water management. Water removal and moisture control via dew point modelling. 3rd Oxyfuel Combustion Conference, Ponferrada, Spain, September 2013

$22 \mathrm{Hu}$, Yukun: Oxy-coal combustion and its integration with power systems for $\mathrm{CO}_{2}$ capture, KTH Thesis, Stockholm, Sweden. February 2013 